EPJ Web of Conferences 12, 04001 (2011)

DOI: $10.1051 /$ epjconf/20111204001

(C) Owned by the authors, published by EDP Sciences, 2011

\title{
Performance assessments insights on the use of cements in waste management
}

\author{
D. Esh ${ }^{1, a}$, J. Philip ${ }^{1}$ and K. Snyder ${ }^{2}$ \\ ${ }^{1}$ U.S. Nuclear Regulatory Commission, Washington, DC 20555, USA \\ ${ }^{2}$ National Institute of Standards and Technology, Gaithersburg, MD 20899, USA
}

\begin{abstract}
The use of cementitious materials has been proposed in a variety of waste management systems because these materials can have a variety of desirable performance characteristics: hydraulic isolation, chemical isolation, structural stability. Cementitious barriers are commonly engineered with a goal of achieving the highest quality material possible (e.g. minimizing hydraulic conductivity, porosity, tortuosity, diffusivity). However, a single performance goal may not be optimum when practical considerations of designs and performance characteristics are considered simultaneously. In addition, laboratory-scale optimized designs may have field-scale characteristics that are less than ideal.
\end{abstract}

Abstracted performance assessment calculations are used to develop risk insights for the performance of cementitious materials in waste disposal or remediation applications. The generic applications considered are the use of cements as a waste matrix (i.e., the radioactivity is incorporated into the hydrating cement matrix) and the use of cements as a resistive barrier (i.e., the radioactivity comes into contact with a hydrated cement matrix) to reduce water contact and decrease mobilization from residual radioactivity remaining in a closed waste storage tank or other system undergoing remediation. Uncertainty analysis using genetic algorithms is used to identify key variables and uncertainties. In addition, stylized calculations are performed to demonstrate the importance of conceptual model uncertainty. Designs with real features are evaluated and compared to idealized representations.

\section{INTRODUCTION}

Cementitious materials are used in a variety of waste management applications, including but not limited to, waste matrices (e.g. wasteforms) and resistive barriers (e.g. vaults). The advantages of these materials are their historical experience base relative to other engineered materials, their cost, and their desired performance characteristics for hydrologic, chemical, and structural components. In many applications, technical assessments of system performance, termed performance assessments, are used to estimate performance well into the future. Performance assessments are used to estimate the impacts associated with changes to a facility/structure/element as a result of events and processes. Frequently, the design process for developing cementitious materials used in waste disposal applications is focused on achieving the highest quality material; commonly developed using small-scale laboratory experiments. In many cases, the laboratory experiments focus on a single performance characteristic (e.g. hydraulic conductivity) whereas the performance of the system is determined by multiple characteristics. The aforementioned design process can result in substantially less than optimum designs with respect to long-term system performance in limiting risk to people and the environment.

\footnotetext{
ae-mail: david.esh@nrc.gov
}

This is an Open Access article distributed under the terms of the Creative Commons Attribution-Noncommercial License 3.0, which permits unrestricted use, distribution, and reproduction in any noncommercial medium, provided the original work is properly cited. 


\section{EPJ Web of Conferences}

\section{DESCRIPTION OF THE WORK}

A simulation model was developed to illustrate key performance variables for two different types of cement systems: waste matrices and resistive barriers. Performance assessment models are systemlevel models; they represent the integrated effects of different process models. The output from one process model may be passed to or incorporated into a different embedded process model. For example, a performance assessment model may include an explicit model for the infiltration of water into the subsurface overlying a buried system as well as a model for the geochemistry of the environment surrounding a waste matrix. Performance assessment models may also use simplified representations of more complex process models through a process called abstraction. Abstraction is used for a variety of reasons including but not limited to the following: 1) to promote understanding, 2) to lessen computational burden, and 3) to facilitate model development. The goal of abstraction is to preserve the essential model responses with less detailed representations. The simulation model developed for this evaluation uses simplified and abstracted submodels.

\subsection{System description}

Figure 1 is a representation of the systems considered in this evaluation. A buried near-surface concrete vault is analyzed, with and without a cementitious wasteform contained within the vault. The vault is

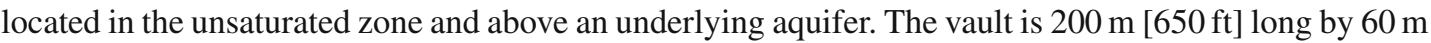
[200 ft] wide by $8 \mathrm{~m}$ high [ $25 \mathrm{ft}$ ]. The vault walls are $0.3 \mathrm{~m}$ [12 in] thick and the floor and roof are $0.45 \mathrm{~m}$ [18 in] thick. The vault is assumed to be constructed of reinforced concrete using ordinary portland cement (OPC). In the first case, the wasteform binder is represented by a tertiary blend of cement, fly ash, and blast furnace slag. The radioactivity is contained within the wasteform. In the second case, the same amount of activity is assumed to be contained within the vault as in the first case, but the activity is evenly distributed over the volume of the vault in a matrix with very limited performance capabilities. The wasteform is assumed to contain $2 \times 10^{13} \mathrm{~Bq}[600 \mathrm{Ci}]$ of ${ }^{99} \mathrm{Tc}$ and $1.5 \times 10^{11} \mathrm{~Bq}$ [4 Ci] of ${ }^{226} \mathrm{Ra}$. These radionuclides were selected to demonstrate the impacts of a relatively soluble and mobile radionuclide that can be significantly impacted by redox conditions in the wasteform $\left({ }^{99} \mathrm{Tc}\right)$ and a moderately soluble and moderately mobile radionuclide $\left({ }^{226} \mathrm{Ra}\right)$ that isn't expected to be significantly impacted by redox condition.

\subsection{Model description}

The model was developed with the software package GoldSim ${ }^{1}$ [1]. The GoldSim software package is a visual model building platform for performing dynamic, probabilistic simulations. GoldSim provides a Radionuclide Transport module, which has built-in elements that can simulate radioactive decay and ingrowth, advection, dispersion, adsorption, diffusion, and matrix diffusion for fractured flow. The model used in this analysis is composed of more than 2,600 GoldSim elements and contains abstracted submodels for key processes. Parameter and model uncertainty are included in the analysis through the use of more than 300 stochastic parameters (i.e. probability distribution functions), though many of them are replicated to perform similar but not identical tasks. There are approximately 50 stochastic parameters that are important for a calculation for a specific radionuclide. The focus of this paper is on cementitious materials, and thus the model description emphasizes the source term and near field release

\footnotetext{
${ }^{1}$ Certain commercial equipment, instruments, or materials are identified in this paper in order to specify the experimental procedure adequately. Such identification is not intended to imply recommendation of endorsement by the National Institute of Standards and Technology, nor is it intended to imply that the materials or equipment indentified are necessarily the best available for the purpose.
} 


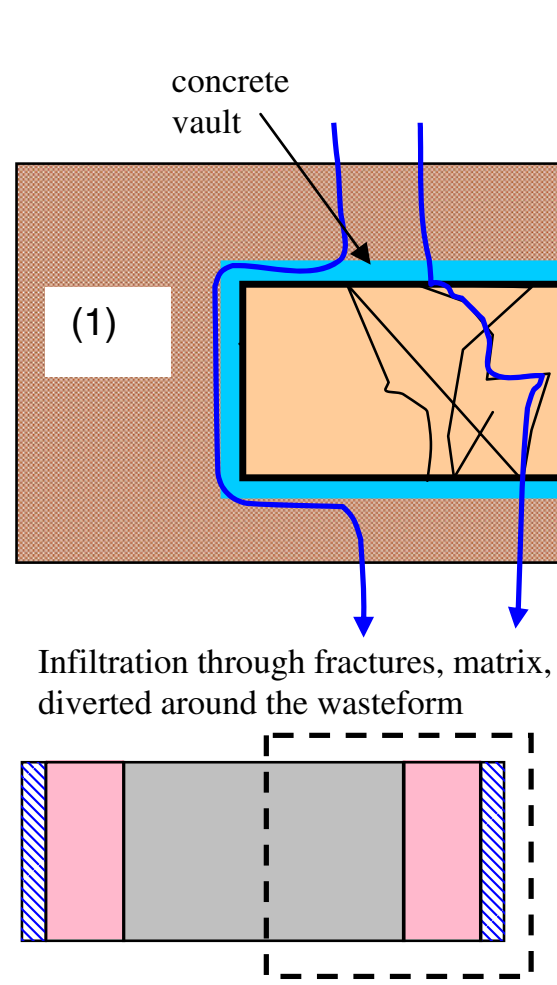

soil

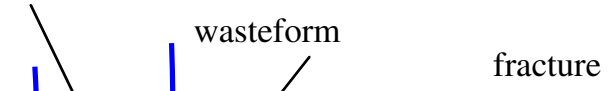

......

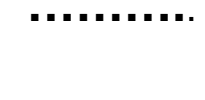

Modeled domain, number of half cells depends on user defined fracture spacing

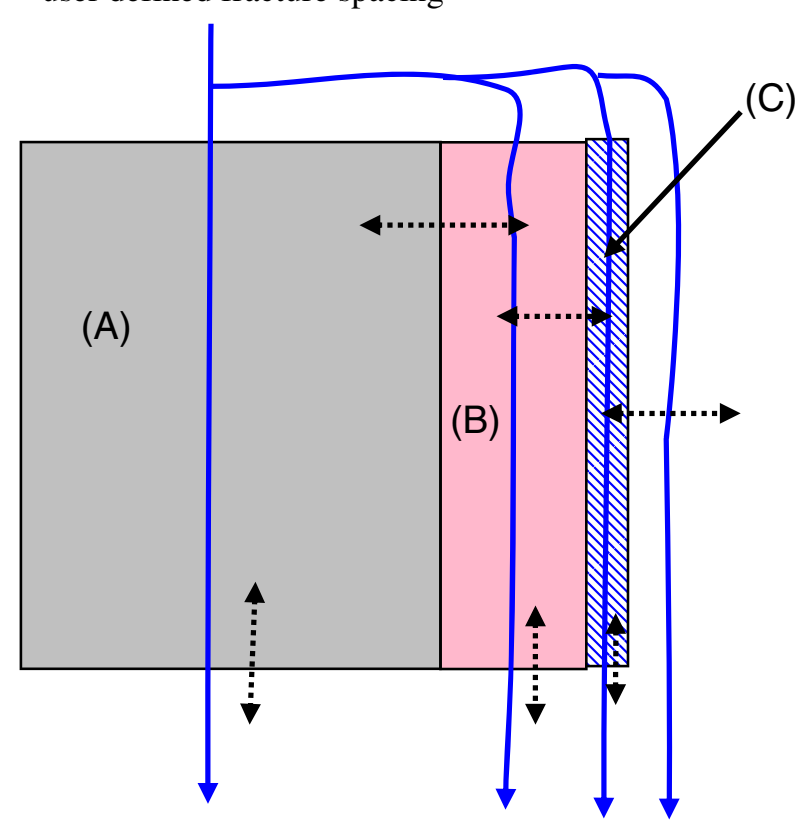

Each region has unique physical and chemical properties (e.g., $\mathrm{K}_{\mathrm{d}}$ values, radionuclide solubilities, hydraulic conductivity)
(A) Intact region
(B) Oxidized region
(C) Degraded region

Diffusion and advection can occur between regions and the external environment

Figure 1. Representation of a buried near surface waste disposal vault including the conceptual model for degradation and water flow. 
components. Process simulation capability of the model includes:

- Infiltration of water to the vaults (including modification to the infiltration rate from an engineered cap),

- Radioactive decay and ingrowth, sorption, solubility limits, advection, dispersion, and diffusion through and between the wasteform (as applicable), vault walls, surrounding soils, unsaturated zone, and underlying aquifer,

- Fractures or shrinkage gaps between the wasteform and vault, and

- Degradation, oxidation, and fracturing of the wasteform.

The source term and near-field release submodels represent infiltration, cap degradation, source oxidation and degradation, and radionuclide transport through the unsaturated zone. Advective flow is modeled as vertical flow through the waste while both vertical and lateral diffusive fluxes are modeled. Diffusive areas between regions are modified based on the estimated volumetric water content of each region. Radionuclides are partitioned between the solid phases (e.g., wasteform, vault, soil) and the pore fluids using a distribution coefficient approach. Solubility limits are applied to the pore fluids, and different solubility limits can be applied to different regions of the model to simulate different chemical environments. For example, the pore fluid in the wasteform is expected to be highly alkaline, whereas the groundwater in the saturated zone is more neutral even when modified by fluids released from the facility.

The cementitious wasteform is assumed to contain blast furnace slag to create reducing conditions in the wasteform. Reducing conditions are beneficial primarily because reduced forms of technetium typically are much less mobile than oxidized forms of technetium. Waste oxidation and degradation are modeled as proceeding from waste surfaces, including the surfaces of cracks, inward (Figure 1). Wasteform cracking may occur during curing, as a result of settlement, or as a result of other processes. The model does not predict the amount of cracking that will occur in the waste form. Instead, the potentially complex pattern of cracking in the wasteform is represented in the model as a series of planar cracks through the waste [Figure 1, item (3)]. The spacing of the cracks is represented with a stochastic variable that the user controls to represent different degrees of fracturing of the waste. In the model, infiltrating water is routed around or through the wasteform based on the quantity of water infiltrating the top of the wasteform and the hydraulic properties of the material [Figure 1, item (1)]. At each fracture or exposed surface, an oxidation front OT(t) and a degradation front DT(t) are estimated to give the respective depth of penetration into the material. The oxidation and degradation fronts may propagate at different rates, resulting in different thicknesses of material that are oxidized or degraded. The rates of front propagation are estimated from empirical models [2, 3] and were previously described [4]. The empirical models for wasteform degradation and oxidation that have been implemented in the performance assessment model do not necessarily represent the dominant mechanisms of degradation and oxidation of the wasteform. Rather, the models serve as plausible representations to evaluate timedependent degradation or oxidation of the wasteform for this study.

In the conceptual model, there are three regions in the wasteform: intact, oxidized, and degraded. The predicted release of radionuclides from each region of waste is affected by the modeled physical and chemical properties of the waste in each region. The actual degraded wasteform may have an extremely complicated collection of units of intact material with variable volumes and shapes. The potentially complicated geometry was simplified into three connected cells in the length dimension of the facility: one for each of the intact, oxidized, and degraded regions. The wasteform was assumed to be broken into a series of blocks by fractures extending through the wasteform. Therefore, the results from the three cells were scaled up to represent the total number of blocks in the system based on the total length of the facility and the assigned fracture spacing. Infiltrating water flows through the fractures were estimated from the unsaturated hydraulic conductivity as a function of the fracture aperture and the volumetric water content. Typically, the amount of water flowing through the fracture relative to the wasteform results in a near zero concentration boundary condition at the exposed side of the wasteform. The dimensions of the blocks in the model were determined by the physical dimensions of the system $(8 \mathrm{~m}$ 
high by $30 \mathrm{~m}$ thick) and the user-defined stochastic fracture spacing distribution. Half of a degrading block was represented in the model and the results were extrapolated to the whole block by invoking a symmetry argument from the midpoint of a block [Figure 1, item (3)]. Diffusive transport between the three regions of the wasteform and from the wasteform to the surrounding vault or connected fractures was represented in the model.

In the conceptual model, the total water flow through the degraded fraction of the waste depends on two conditions: if water flowing into the intact fraction exceeds the capacity of that fraction to transmit water; if water flowing into the intact and oxidized fractions of the waste exceeds the capacity of those fractions to transmit water. Any additional flow is made available to the planar fractures that bound the side of the cell network next to the degraded region of the wasteform. Although each fracture does have finite capacity, for the fractures considered in this analysis the saturated hydraulic conductivity was sufficient to transmit the remaining flow. In summary, advective flow through the intact, oxidized, and degraded fractions is based on the assumption that water will flow through the waste vertically. The amount of flow predicted to occur through each type of waste is calculated based on the horizontal surface area of the type of waste (i.e., intact, oxidized, or degraded) and the hydraulic conductivity for the type of waste.

Oxidized waste is waste in which oxygen from groundwater diffuses into the waste and consumes the reducing capacity of the wasteform. In the oxidized fraction of the waste, the sorption coefficient of technetium is much lower (i.e., $1 \mathrm{~mL} / \mathrm{g}$ ) than it is in the reducing fraction of the waste (i.e., $500 \mathrm{~mL} / \mathrm{g}$ ). As previously discussed, oxidation is modeled based on a shrinking core model [2-4]. Oxidation is modeled to occur from each exposed surface of the waste, including the surfaces of fractures. The depth to which the waste is predicted to oxidize is limited by the diffusion of oxygen through water into the wasteform. Steady-state partially saturated conditions are represented except for the fractures, which have transient partially saturated conditions determined by the infiltration rate and permeability of the fractures.

\section{RESULTS}

The evaluation defined distinct scenarios to illustrate system performance, and to illustrate the impact of key uncertainties and practical considerations. The first scenario evaluated was an idealized case (identified as A001) where the key parameters are provided in Table 3. This case represents a system assigned idealized homogeneous properties estimated from laboratory measurements of small-scale samples. The assumptions are very limited oxidation or degradation for the wasteform as well as low infiltration to the vault. The hydraulic properties of the vault and wasteform determine how much solution flows through the waste. Table 4 provides the results and the description of the set of analyses used to develop risk insights into the performance of buried cementitious wasteforms and vaults. Unless indicated otherwise, the results are for a cementitious wasteform. The results in Table 4 for additional cases are presented as normalized values to the A001 idealized representation. Figure 2(a) provides a representative horsetail plot of the individual realizations from case A001 to illustrate the variance in the results from 100 realizations (Each case was simulated probabilistically). Figure 2(b) provides the mean result for the each case from Table 4 with a cementitious wasteform (designated by an 'A'). The values used to calculate the ratios in Table 4 were the peak of the mean result for each case for both radionuclides. Uncertainty analysis was performed using a genetic variable selection algorithm that has been discussed previously [4].

\section{DISCUSSION}

A variety of cases were simulated to develop risk insights into the performance of near-surface waste disposal facilities utilizing cementitious materials. Idealized representations of waste disposal facilities are needed to understand the optimum performance. However, starting the design process from the 
Table 1. Key parameters for the idealized case (A001).

\begin{tabular}{|c|c|c|c|}
\hline Parameter & Description & Units & Value or distribution \\
\hline $\mathrm{Kh}_{\mathrm{i}}$ & $\begin{array}{l}\text { Saturated hydraulic conductivity of the } \\
\text { intact region of the wasteform }\end{array}$ & $\mathrm{cm} / \mathrm{s}$ & $1 \mathrm{E}-11$ to $1 \mathrm{E}-10$, uniform \\
\hline $\mathrm{Kh}_{\mathrm{o}}$ & $\begin{array}{l}\text { Saturated hydraulic conductivity of the } \\
\text { oxidized region of the wasteform }\end{array}$ & $\mathrm{cm} / \mathrm{s}$ & 1E-11 to $1 \mathrm{E}-10$, uniform \\
\hline $\mathrm{Kh}_{\mathrm{d}}$ & $\begin{array}{l}\text { Saturated hydraulic conductivity of the } \\
\text { degraded region of the wasteform }\end{array}$ & $\mathrm{cm} / \mathrm{s}$ & $1 \mathrm{E}-10$ to $1 \mathrm{E}-9$, uniform \\
\hline $\mathrm{Kh}_{\mathrm{v}}$ & $\begin{array}{l}\text { Saturated hydraulic conductivity of the } \\
\text { vault }\end{array}$ & $\mathrm{cm} / \mathrm{s}$ & $1 \mathrm{E}-10$ to $1 \mathrm{E}-9$, uniform \\
\hline$\Phi$ & Waste porosity & unitless & 0.25 to 0.35 , uniform \\
\hline $\mathrm{F}$ & Fracture spacing & $\mathrm{m}$ & $\mathrm{a}$ \\
\hline De & Diffusion coefficient waste & $\mathrm{cm}^{2} / \mathrm{s}$ & $5 \mathrm{e}-11$ to $1.5 \mathrm{e}-10$, uniform \\
\hline $\mathrm{De}_{\mathrm{v}}$ & Diffusion coefficient vault & $\mathrm{cm}^{2} / \mathrm{s}$ & 5e-11 to $1.5 \mathrm{e}-10$, uniform \\
\hline DT & $\begin{array}{l}\text { Cumulative one-dimensional degradation } \\
\text { front propagation over } 10,000 \text { years }\end{array}$ & $\mathrm{cm}$ & $\mathrm{b}$ \\
\hline OT & $\begin{array}{l}\text { Cumulative one-dimensional oxidation } \\
\text { front propagation over } 10,000 \text { years }\end{array}$ & $\mathrm{cm}$ & $\mathrm{c}$ \\
\hline I & Long-term infiltration rate & $\mathrm{cm} / \mathrm{yr}$ & 0.3 to 0.4 , uniform \\
\hline
\end{tabular}

Material Subscripts $-\mathrm{v}=$ vault, $\mathrm{i}=$ intact, $\mathrm{o}=$ oxidized, $\mathrm{d}=$ degraded

a - no fractures in case A001,

$\mathrm{b}$ - less than $0.1 \mathrm{~mm}[0.004 \mathrm{in}]$ in case A001,

$\mathrm{c}-$ less than $0.1 \mathrm{~mm}[0.004 \mathrm{in}]$ in case A001.

optimum point can result in less than optimal and possibly even unfavorable results with respect to long-term performance. As discussed above, the first case evaluated (A001) was an idealized case used as a benchmark to illustrate the relative change for the additional analyses. In Case A001, there is very little flow through the wasteform, no fracturing, minimal degradation, and therefore very good performance. Waste form development, in many cases, is focused on achieving the best matrix possible, where 'best' is defined by the lowest permeability matrix determined with smallscale laboratory samples using surrogate samples. If the best matrix also resulted in a material that was easily implemented in the field, did not fracture or experience shrinkage, and did not degrade, the waste form development approach would be successful. However, many engineered materials can have properties in the field that differ significantly from those achieved in the lab, and may experience fracturing, shrinkage, and degradation [5].

Case A002 differs from A001 only in the waste matrix properties. The resultant ratios of Tc and $\mathrm{Ra}$ to Case A001 are 3 and 40, respectively. Case A003 consists of fractures with a nominal spacing of $10 \mathrm{~m}$ [33 ft]. Case A003 has a larger peak Tc dose relative to Case A002 but a smaller increase for the Ra dose. The introduction of fractures results in a shorter diffusive path length and more exposed surface area per unit volume of material. If the radionuclide is not strongly sorbed, or has limited solubility, the additional exposed surface area and shorter transport length results in a comparable increase in release. A material that experiences moderate cracking or shrinkage can have less favorable performance, even with ideal matrix properties, than a material designed to have very limited cracking or shrinkage but less than optimum matrix hydraulic properties. Diffusion can be a dominant transport mechanism when water flow rates are low. In all the simulations presented here, diffusion contributed significantly to release (e.g. diffusion to regions where water flow was concentrated).

Case A004 provides for a small amount of degradation and oxidation of the wasteform over 10,000 years. Tc releases are impacted because Tc is much more easily released when in an oxidized form 
Table 2. Scenario descriptions and simulation results.

\begin{tabular}{|c|c|c|c|c|}
\hline $\begin{array}{l}\text { Case } \\
\text { ID }\end{array}$ & $\begin{array}{c}\text { Case } \\
\text { Description }\end{array}$ & Description & $\begin{array}{c}{ }^{99} \mathbf{T c} \\
\text { Ratio* }\end{array}$ & $\begin{array}{l}{ }^{226} \mathbf{R a} \\
\text { Ratio* }^{*}\end{array}$ \\
\hline $\mathrm{A} 001$ & $\begin{array}{l}\text { Ideal vault and } \\
\text { wasteform }\end{array}$ & $\begin{array}{l}\text { Idealized case - small-scale laboratory } \\
\text { measurements of surrogate samples. No } \\
\text { degradation. Parameterization described } \\
\text { in the text. }\end{array}$ & 1 & 1 \\
\hline $\mathrm{A} 002$ & Field properties & $\begin{array}{c}\text { 100x larger Kh's (all regions) } \\
\text { 100x larger De } \\
\text { Waste porosity }=[0.45-0.55] \text { uniform }\end{array}$ & 3 & 40 \\
\hline A003 & Fractures & $\mathrm{F}=10 \mathrm{~m}$ & 10 & 10 \\
\hline $\mathrm{A} 004$ & Degradation & $D T=5.3 \mathrm{~cm}, O T=5.5 \mathrm{~cm}$ & 4 & 1 \\
\hline $\mathrm{A} 005$ & $\begin{array}{l}\text { Field properties }+ \\
\text { Fractures }\end{array}$ & $\begin{array}{c}\text { 100x larger Kh's } \\
F=10 \mathrm{~m}\end{array}$ & 8 & 60 \\
\hline A006 & $\begin{array}{l}\text { Field properties }+ \\
\text { Fractures }+ \\
\text { Degradation }\end{array}$ & $\begin{array}{c}\text { 100x larger Kh's } \\
F=1 \mathrm{~m} \\
\text { DT }=5.3 \mathrm{~cm}, \text { OT }=5.5 \mathrm{~cm}\end{array}$ & 70 & 80 \\
\hline A007 & $\begin{array}{l}\text { Case A006 + non- } \\
\text { ideal cap }\end{array}$ & $\begin{array}{c}\text { As indicated for A006 } \\
\text { Infiltration increased to } 10-15 \mathrm{~cm} / \mathrm{yr}\end{array}$ & 700 & 30,000 \\
\hline B001 & Ideal vault & $\begin{array}{l}\text { Identical to case A001 but no credit for } \\
\text { wasteform, only the vault. }\end{array}$ & $1^{\mathrm{a}}$ & $1^{\mathrm{a}}$ \\
\hline B002 & $\begin{array}{l}\text { Field properties } \\
\text { vault }\end{array}$ & 10x larger $\mathrm{Kh}$ & 9 & 10 \\
\hline B003 & Fractures & Fractured vault & 260 & 70 \\
\hline
\end{tabular}

* - the ratios are calculated relative to the results for case A001. For example, the Ratio in the next to the last column for Case A002 is calculated as (peak Tc dose for A002/peak Tc dose for A001). $\mathrm{a}-$ results for cases B001, B002, and B003 are relative to B001.

compared to reduced forms. However, because the wasteform is not assumed to be fractured in this case, the amount of waste degraded is small relative to the volume of waste $(\sim 1.4 \%)$ and therefore the Ra release is relatively unaffected. As shown in Case A006, degradation and oxidation can be much more significant if the geometry and surface area of the waste is different (even when the basic rate of degradation or oxidation front propagation is the same). The presence of fractures increases the amount of waste degraded or oxidized over 10,000 years to approximately $10 \%$ by volume.

Case A005 is interesting because the result is not intuitive. Case A005 is a combination of field properties for the matrix and the presence of a moderate amount of fracturing. Whereas the release of $\mathrm{Ra}$ is higher in the combined case, the release of Tc is lower than either of the results for Cases A002 and A003. This result is driven by the competition between advection and diffusion to release material from different zones or regions on the wasteform model. Because advection and diffusion can have different effective response times as to when a peak release may occur, it may not be intuitive what would constitute a conservative choice for wasteform release modeling or even for wasteform design. Representations or designs that spread releases temporally and spatially result in lower risk.

Cases A006 and A007 were designed to illustrate the combined effect of processes or uncertainties under two different states of the overall system. Case A006 has matrix properties representative of field materials, fracturing, and degradation for a system with relatively low infiltration rate ( 3 to $4 \mathrm{~mm} / \mathrm{yr}$ ) [0.12 to $0.16 \mathrm{in} / \mathrm{yr}$ ] which may be representative of a system located in an arid or semi-arid climate. Case A007 is identical to Case A006 except the infiltration rate was increased to a range more representative of a humid climate $(10-15 \mathrm{~cm} / \mathrm{yr})$ [[4-6] in/yr]. In each case, the combined effect of the uncertainties 


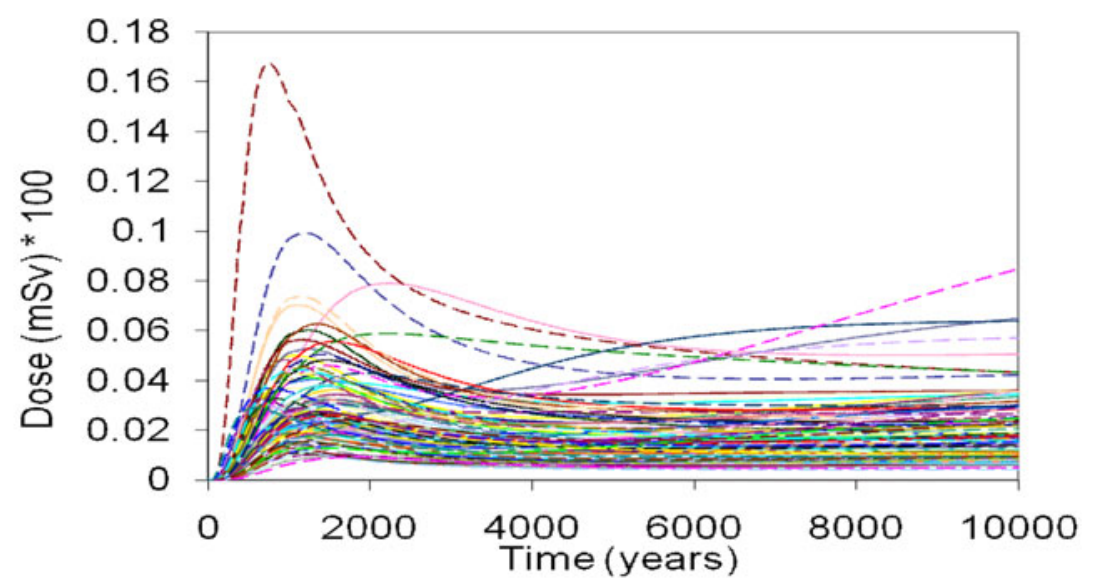

(a)

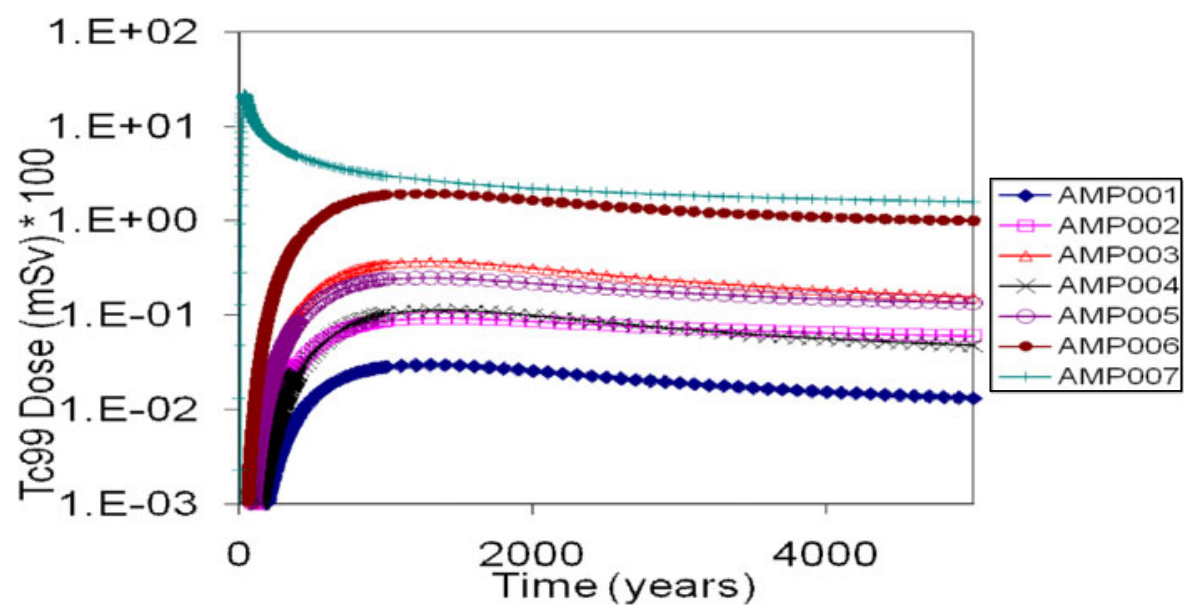

(b)

Figure 2. The horsetail plot of ${ }^{99} \mathrm{Tc}$ for case A001; (b) The mean results for ${ }^{99} \mathrm{Tc}$ for the cases with a cementitious wasteform.

is significantly larger than any individual uncertainty. Case A007 demonstrates a strong sensitivity to water flow, though the impact is much larger for Ra than for Tc. When Tc is in the oxidized or degraded zones of the wasteform, it is highly soluble and relatively non-sorbing. Whereas Ra is still moderately sorbing and, therefore, releases of it are more strongly influenced by the overall availability of water to the wasteform.

In addition to evaluating the wasteform uncertainties, a few cases were developed to perform a similar analysis for a resistive barrier (e.g. vault). Case B001 is used to represent an ideal vault. In this case the waste is not assumed to be bound in a robust matrix; the source term is placed in a media with hydraulic and sorption properties similar to sand. The hydraulic and diffusive properties of the vault limit the release of waste. Case B002 consisted of hydraulic properties for the vault that were representative of field-emplaced properties reflecting inadequate quality assurance (e.g. 10x increase). The ratio for Tc was 9 and the ratio for Ra was 10, respectively. Case B003 represented a fractured vault, where flow can bypass a portion of the matrix of the vault floor. The ratio for Tc was 260 and the ratio for Ra was 70, 
AMP 2010

respectively. For a resistive type barrier, having high confidence in the future integrity of the barrier is more important than optimizing the resistivity of the barrier.

Uncertainty analysis was performed on select cases to illustrate how it can be used to compliment case- or scenario-based evaluation of key uncertainties and to confirm interpretation of the results from individual cases. Uncertainty analysis of the model output was performed using neural network software developed by Neuralware [6]. Neuralworks Predict@is an add-in to Microsoft Excel that can be used to build neural networks. The approach used in this analysis was to export the sampled stochastic input variables along with the pertinent output variable (e.g., dose for a particular radionuclide at a particular time) from the model to Excel. To build the network, the software uses genetic algorithms to search for synergistic sets of input variables that are good predictors of the output. The software also can perform a pre-selection of variables using a cascaded genetic algorithm approach. This method gives more consistent variable sets by pruning out variables which are consistently rejected by different invocations of the genetic algorithm. U.S. Nuclear Regulatory Commission (NRC) experience with applying this technique for uncertainty analysis suggests it is quite powerful at identifying key input variables while eliminating spurious correlations, a common problem with large data sets of many input variables.

The uncertainty analysis for Case A003 identified three primary variables driving the variance in the output of the Tc dose: fracture width (used to calculate flow through the fractures), hydraulic conductivity of the intact grout, and the groundwater flow rate (primarily influences the amount of dilution prior to ingestion by a receptor). The uncertainty analysis for Case A006 identified five primary variables driving the variance in the output of the Tc dose: the fracture width and groundwater flow rate as in Case A003, the parameter Nm used in the degradation rate calculation, the intact grout hydraulic conductivity, and the degraded grout hydraulic conductivity. With the exception of the groundwater flow rate, these variables all relate directly to the release of Tc from the wasteform. By comparison, different variables had the most influence on the Ra dose for Case A006: infiltration rate, fracture width, groundwater flow rate, distribution coefficient for Ra in the unsaturated zone, and the distribution coefficient for $\mathrm{Ra}$ in the degraded region of the waste. The key variables for Ra tend to be those that influence the timing of the Ra dose because the peak Ra dose was at the end of the simulation period (10,000 years). In the case of a resistive barrier (B002), the uncertainty analysis identified the hydraulic conductivity of the vault floor, the groundwater flow rate, and the partition coefficient of Tc in the waste as the key variables. Even a small amount of sorption in the waste can be important when resistive barriers are used.

\section{CONCLUSIONS}

The analysis of the long-term performance of cementitious materials in waste management applications identified key features and processes that, with adequate understanding and additional research, may reduce uncertainty in long-term predictions. For cementitious wasteforms, initial fractures or shrinkage, processes that form fractures, or features and processes that contribute to degradation are essential to understanding long-term performance. For resistive barriers such as a vault or other containment structure, the features and processes that affect the integrity of the barrier and its hydraulic properties are important. A variety of risk insights were derived from the assessment of select cementitious barriers used in waste disposal applications:

- The best designs for long-term performance will be developed by considering both uncertainties and the influence of the system on the barriers.

- Uncertainties and coupling of processes can result in non-intuitive results with respect to barrier performance.

- Conservative modeling choices may be difficult to identify without performing modeling to evaluate each choice.

- Though most attention is placed on advection, diffusive processes (especially for degraded materials) can have equal or greater importance with respect to long-term performance. 
EPJ Web of Conferences

\section{References}

[1] GoldSim Technology Group, GoldSim Probabilistic Simulation Environment. GoldSim Technology Group, LLC. Issaquah, WA, (2004).

[2] Walton, J.C., L.E. Plansky, and R.W. Smith, Computer Models for the Estimation of Service Life of Concrete Barriers, NUREG/CR-5542, U.S. Nuclear Regulatory Commission, Washington, DC, (1990).

[3] Smith, R.W. and J.C. Walton, "The Role of Oxygen Diffusion in the Release of Technetium from Reducing Cementitious Waste Forms.” Mat. Res. Soc. Symp. Proc. U 294: 247, (1993).

[4] Esh, D. W., A. C. Ridge, and M. Thaggard, Development of Risk Insights For Regulatory Review of a Near-Surface Disposal Facility of Radioactive Waste, Waste Management 06 Proceedings, Tuscon, AZ, (2006).

[5] Simpkins, A. et al., Review of Literature and Assessment of Factors Relevant to Performance of Grouted Systems for Radioactive Waste Disposal, Center for Nuclear Waste Regulatory Analyses, San Antonio, TX, (2009).

[6] Neuralware, NeuralWorks Predict@Product Version 2.40, Carnegie, PA, (2001). 